Удк 378

\title{
ПРЕПОДАВАНИЕ ФИЛОСОФИИ И СОЦИОЛОГИИ В СИСТЕМЕ ДИСТАНЦИОННОГО ОБУЧЕНИЯ В УСЛОВИЯХ ПАНДЕМИИ КОРОНАВИРУСА
}

\author{
Аверин Александр Николаевич \\ доктор философских наук, профессор \\ Выжигин Александр Юрьевич \\ кандидат технических наук, доцент \\ Тонконогов Александр Викторович \\ доктор философских наук, доцент, профессор \\ Шишков Василий Валерьевич \\ кандидат политических наук, доцент \\ Российская академия народного хозяйства \\ и государственной службы при Президенте РФ
}

Аннотация: В статье рассматривается опыт преподавания философии и социологии студентам первого курса Российской академии народного хозяйства и государственной службы при Президенте Российской Федерации в условиях распространения пандемии коронавируса, возникающие в этом процессе трудности и недостатки.

Ключевые слова: Задание, образовательный контент, промежуточная аттестация, система дистанционного обучения, тест.

\section{TEACHING PHILOSOPHY AND SOCIOLOGY IN DISTANCE LEARNING IN THE CONTEXT OF THE CORONAVIRUS PANDEMIC}

\author{
Averin Alexander \\ Vyzhigin Alexander \\ Tonkonothov Alexander \\ Shishkov Vasily
}

\footnotetext{
Abstract: The article examines the experience of teaching philosophy and sociology to first-year students of the Russian Academy of National Economy and 
Public Service under the President of the Russian Federation in the context of the spread of the pandemic of coronavirus, the difficulties and shortcomings arising in this process.

Key words: Sets, educational content, intermediate certification, distance learning system, test.

Авторы статьи вначале ознакомились с нормативными правовыми документами по использованию электронного обучения и дистанционных образовательных технологий $[1,2]$. Прошли обучение по программам повышения квалификации - Современные научно-педагогические технологии обеспечения образовательной и научной деятельности в университете (с применением дистанционных образовательных технологий) в Российском экономическом университете имени Г.В. Плеханова; в академии: Актуальные проблемы современного образования: инклюзивный подход и информационно-коммуникационные технологии; Формирование контента курса в системе дистанционного обучения и его использование в учебном процессе (КПК «Использование СДО в образовательном процессе с применением электронного обучения и дистанционных образовательных технологий (ЭО и ДОТ)»; Перекрестная проверка: стратегия и технология реализации». Принимали участие в работе вебинаров по проблемам дистанционного образования, просматривали видеоролики о работе в системе дистанционного обучения. Изучали академические методические материалы - Перевод образовательного процесса Академии на использование дистанционных образовательных технологий (на период карантина); Инструкция по авторизации в СДО Академии; Инструкция для преподавателей (авторов) онлайн-курсов в СДО РАНХиГС; Инструкция для преподавателей (авторов) по формированию контента и работе в СДО Академии; Использование дистанционных образовательных технологий для организации образовательного процесса (инструкция для преподавателей); Навигация по списку курсов в СДО.

Автор курса самостоятельно размещает образовательный контент курса, автор курса и преподаватели читают лекции и проводят семинарские занятия, отслеживают работу студентов, выставляют им оценки. Представление образовательного контента в системе дистанционного обучения включает размещение рабочих программ дисциплин, тематики лекции и семинарских 
занятий, планов семинарских занятий, текстов лекций, комплектов тестов и заданий, инструкции по работе с курсом. В планах семинарских занятий указаны темы, количество часов на каждую тему, основная и дополнительная литература, тематика докладов, вопросы для подготовки к промежуточной аттестации. Для студентов по специальности «Экономическая безопасность» в планах семинарских занятий даны подготовленные автором курса Методические рекомендации по подготовке эссе по философии.

Тестовые задания к лекциям обязательны для выполнения студентами и размещаются для всех студентов курса. По каждому лекционному занятию дается 5 тестов по 5 вопросов в каждом тесте. Количество тестов зависит от количества лекционных занятий. В соответствии с учебным планом может быть 12 (24 часа) или 8 (16 часов) занятий. При наличии 12 занятий дается 300 тестов, 8 занятий - 200 тестов. На выполнение тестов по каждому занятию отводится 6 дней. Количество попыток и время ответа на тесты не ограничены. Предполагается, что это стимулирует студентов для поиска правильного ответа. В образовательной программе, в которой семинарские занятия проводил один автор курса, размещаются задания для всех студентов академических групп. Ответ на задание студенты представляют на одной странице листа А4. По каждой теме дается 5 заданий. Количество заданий зависит от количества семинарских занятий. В соответствии с учебным планом может быть 16 (32 часа), 12 (24 часа) или 8 (16 часов) занятий. При наличии 16 занятий размещается 80 заданий, 12 занятий - 60 заданий, 8 занятий - 40 заданий. На выполнение заданий по каждому семинарскому занятию отводится 6 дней. Ответы на тесты и задания можно найти при изучении текстов лекций. В образовательных программах с участием нескольких преподавателей каждый преподаватель размещает задания для студентов академических групп, в которых он проводит семинарские занятия.

Лекционные и семинарские занятия, чаты, промежуточная аттестация студентов проводятся в дистанционном режиме в Microsoft Teams. Лектор использует ноутбук, студенты - компьютеры, ноутбуки, планшеты, мобильные телефоны. Лекции читаются при включенных у лектора видеокамере и микрофоне. На семинарских занятиях все студенты включают микрофон, отвечающий на вопрос студент включает видеокамеру. При отсутствии на компьютере студента видеокамеры он пользуется видеокамерой, установленной на мобильном телефоне. 


\section{АКТУАЛЬНЫЕ ВОПРОСЫ СОВРЕМЕННОЙ НАУКИ И ОБРАЗОВАНИЯ}

Студенты выполняют тесты в системе дистанционного обучения. Оценка тестов осуществляется автоматически. Ответы на задания студенты загружают в отдельные файлы и размещают их в системе дистанционного обучения. Оценку заданий осуществляет преподаватель по балльной системе за каждое задание. После окончания срока выполнения задания студенты могут давать ответы, при этом количество баллов за ответы по решению преподавателя может уменьшаться или оставаться таким же. Для студентов, обучающихся по специальности «Экономическая безопасность», промежуточная аттестация проводится в форме эссе. Студенты загружают текст эссе в отдельные файлы и размещают их в системе дистанционного обучения. Оценка эссе осуществляется по следующим критериям: знание и понимание студентом учебного теоретического материала по дисциплине «Философия»; умение студента анализировать и критически оценивать информацию; качество изложения материала; качество оформления работы. Авторский личный вклад студента в подготовку эссе оценивается путем самопроверки эссе в системе «Антиплагиат». Для получения оценки «зачтено» по эссе процент оригинального текста должен быть в справке о самопроверке эссе в системе «Антиплагиат» больше 70\%. После выполнения всех тестов и заданий в системе дистанционного обучения отражаются общие баллы оценок за ответы, которые преподаватель, проводящий промежуточную аттестацию, переводит в систему ECTS. Студенты, которые постоянно не посещали семинарские занятия, получили 50 и менее баллов, сдают экзамен, дифференцированный зачет с оценкой или зачет. Студентам, получившим 51 и больше баллов, дается возможность повысить оценку во время экзамена или дифференцированного зачета с оценкой. Для получения оценки «удовлетворительно» необходимо получить 51 - 65 баллов, «хорошо» - от 66 до 80 , «отлично» - от 81 до 100. Оценка «хорошо» предусматривает дифференциацию по балам: D - от 66 до 71 балла - работа выполнена удовлетворительно с заметными недостатками: C - от 72 до 80 баллов правильно выполнена работа с несколькими заметными ошибками; оценка «отлично»: «хорошо» В - от 81 до 90 баллов - знание выше среднего уровня с некоторыми ошибками; А - от 91 до 100 баллов - выдающиеся знания с возможными незначительными погрешностями. Оценка «не удовлетворительно» выставляется при получении 50 и менее баллов: FX - не освоен минимальный (базовый) объем дисциплины. 


\section{АКТУАЛЬНЫЕ ВОПРОСЫ СОВРЕМЕННОЙ НАУКИ}

И ОБРАЗОВАНИЯ

Для студентов, обучающихся по специальности «Экономическая безопасность», учебным планом предусмотрен на втором курсе комплексный экзамен по философии, социологии и истории. Комплексный экзамен проводился в системе дистанционного обучения. Преподаватели проводили консультацию для студентов в Microsoft Teams. В летнюю сессию 2019 - 2020 учебного года комплексный экзамен проводился для всех студентов курса одновременно. Студенты, распределенные на 10 групп по 9 человек в каждой группе, письменно отвечали на три вопроса в билете. Руководитель образовательной программы высылал преподавателям по электронной почте письменные ответы студентов для проверки. Преподаватели выставляли до 33 баллов за ответ на один вопрос соответственно по философии, социологии, истории и оправляли данные руководителю образовательной программы, который выставлял общую оценку. В этом учебном году возможно размещение письменных ответов в системе дистанционного обучения. Вопросы по философии и социологии связаны друг с другом, сформулированы по одной или близкой тематике, представлены в виде заданий, в которых есть теоретическая и практическая части. В содержательном ответе на практическую часть студент излагает свою точку зрения, оценку, свое отношение, мнение о поставленной в вопросе проблеме.

Опыт преподавания философии и социологии в системе дистанционного обучения выявил ряд трудностей и недостатков. В частности, автором курса были получены определенные знания, однако, до введения в академии обязательного преподавания в системе дистанционного обучения у него не было никакого опыта в этой области. Пришлось приобретать умения и навыки непосредственно в процессе преподавания. Работа оказалась трудоемкой и рутинной. Контент курса в системе дистанционного обучения размещается ручным способом. С большим трудом и не сразу удалось освоить размещение тестов, поскольку до этого не была никакого опыта. При наличии нескольких академических групп, в которых проводятся семинарские занятия, необходимо проверять огромное количество письменных ответов студентов на задания. Существует проблема определения уровня качества ответа студентов во время промежуточной аттестации. На проведение зачета отводится 2 академических часа на студенческую группу (в условиях пандемии 80 минут), экзамена - 4 часа (160 минут). Количество студентов в группе - 25 и более. Иначе говоря, существующие нормативы часов для 


\section{АКТУАЛЬНЫЕ ВОПРОСЫ СОВРЕМЕННОЙ НАУКИ И ОБРАЗОВАНИЯ}

приема зачета и экзамена не способствуют повышению качества ответов студентов. На семинарских занятиях присутствует большинство студентов. Во многом это связано с тем, что они должны сдавать преподавателю экзамен или зачет. Как правило, на семинарах в одной академической группе постоянно отсутствовало не более трех - четырех студентов. На лекциях в основном присутствовали студенты академических групп, которые должны проходить промежуточную аттестацию у лектора. Такая же ситуация была раньше при чтении лекций в учебной аудитории.

Подводя итоги, следует отметить, что преподавание философии и социологии в системе дистанционного обучения в условиях распространения пандемии коронавируса является вынужденной, необходимой и оправданной мерой. Вместе с тем в целом система дистанционного обучения не должна заменять личного общения преподавателей и студентов в аудитории. Она может использоваться в качестве вспомогательного средства и дополнять преподавание философии и социологии в очном режиме обучения.

\section{Список литературы}

1. Федеральный закон от 29 декабря 2012 года № 273-Ф3 «Об образовании в Российской Федерации» // Собрание законодательства Российской Федерации. 2012, № 53, ст. 7598; 2020, № 12, ст. 1645; № 22, ст. 3379; № 24, ст. 3738; № 31, ст. 5063.

2. Приказ Министерства образования и науки Российской Федерации от 23 августа 2017 года № 816 «Об утверждении Порядка применения организациями, осуществляющими образовательную деятельность, электронного обучения, дистанционных образовательных технологий при реализации образовательных программ» // Официальный интернет-портал правовой информации" (www.pravo.gov.ru) 20 сентября 2017 г. 